\title{
Update on Management of Viral Hepatitis B
}

\author{
Desmond Wai \\ Department of Hepatology, Asian Centre for Liver Disease and Transplantation, Gleneagles Hospital, Singapore
}

Correspondence: Desmond Wai, Consultant, Department of Hepatology, Asian Centre for Liver Disease and Transplantation Gleneagles Hospital, Singapore, e-mail:dr_desmond_wai@yahoo.com.sg

\section{ABSTRACT}

Management of hepatitis B has gone a long way since the introduction of lamivudine and interferon. Today, we have several much more potent oral antivirals for hepatitis $\mathrm{B}$, which are associated with much less resistance. Pegylated interferon has the path for immune modulation and newer immune modulators are in the pipeline. Options of combination therapy are being evaluated, while treatment is being individualized. Although the best treatment for hepatitis $B$ is yet to be identified, the prospects are brighter than ever before.

Keywords: Hepatitis B, Management.

\section{CHRONIC HEPATITIS B IN BANGLADESH}

As in other parts of Asia, chronic hepatitis B (CHB) is common in Bangladesh. Community studies in Dhaka have showed the prevalence of $\mathrm{CHB}$ to be 5.5 to $5.9 \% .{ }^{1} \mathrm{CHB}$ can lead to liver fibrosis, liver cirrhosis, liver failure and hepatocellular carcinoma (HCC). ${ }^{2}$ Hence, hepatitis B-related morbidity and mortality have a major impact on people of Bangladesh.

\section{CLINICAL PHENOTYPES OF PATIENTS WITH CHB}

1. HBeAg positive CHB: Patients with positive HBeAg, HBV DNA > 20,000 IU/ml, and ALT and AST higher than two times upper limit of normal.

2. HBeAg negative CHB: Patients with negative $\mathrm{HBeAg}$, HBV DNA > 2,000 IU/ml, and ALT and AST higher than two times upper limit of normal.

3. Immunotolerant phase hepatitis B carriers: Patients with positive HBeAg, HBV DNA > 20,000 IU/ml and persistently normal liver enzymes.

4. Inactive hepatitis $B$ carriers: Patients with negative HBeAg, HBV DNA < 2,000 IU/ml and persistently normal liver enzymes.

However, such classification is oversimplied as many patients do not fit into any category. ${ }^{3}$

\section{WHICH HEPATITIS B PATIENT REQUIRES ANTIVIRAL TREATMENT?}

Currently, only patients with HBeAg positive and HBeAg negative CHB are required to take antiviral agents. ${ }^{3}$ Liver biopsy is the gold standard in subclassifying patients with
$\mathrm{CHB}$, as it can determine stage of liver fibrosis and degree of inflammation. For patients with high viral load and significant fibrosis, like presence of bridging fibrosis or cirrhosis, antiviral treatment may be indicated. For patients with high viral load, minimally elevated liver enzymes but unremarkable liver histology, we can afford to wait and monitor without administering antiviral drugs.

Fibroscan is a new device that can estimate degree of liver fibrosis with reasonable accuracy and may replace liver biopsy in some cases. If F2 or higher state of fibrosis is detected on fibroscan, antiviral medication may be initiated. ${ }^{4}$

Patients with cirrhosis and detectable HBV DNA, regardless of their transaminase level, should be treated with antiviral drugs as suppressing their HBV DNA titer has been shown to lead to reduction in deterioration of liver function and development of HCC. ${ }^{5}$

Cumulating data has showed that after resection for HCC, HBV DNA level may predict recurrence and, hence, patients with HCC and detectable HBV DNA should be treated with antivirals. ${ }^{6}$

The REVEAL study, which followed more than 3,000 untreated hepatitis $B$ carriers for more than 10 years, showed that baseline HBV DNA titer of $>2,000 \mathrm{IU} / \mathrm{ml}$ was a significant factor leading to development of hepatitis $B$ cirrhosis and HCC. ${ }^{7}$ Results from the REVEAL study led to the debate among hepatologists on whether a hepatitis $\mathrm{B}$ carrier with normal liver enzymes, unremarkable liver histology, but with HBV DNA > 2,000 IU/ml should be treated with antivirals. On one hand, HBV DNA > 2,000 IU/ml has been showed to higher chance of complications. Yet, there has been no data on such intervention which would be very costly for the population as a whole. Currently, antivirals are not recommended for this category of patients. 
Studies have showed that inactive hepatitis B carriers would develop reactivation of hepatitis B while on immunosuppressants, such as corticosteroids and chemotherapy drugs. Such reactivation may lead to a severe flares and even acute liver failure. It is recommended that hepatitis B be routinely screened in patients prior to initiation of immunosuppressants, and antivirals be started till 6 months after last dose of immunosuppressants.

\section{WHAT IS THE ENDPOINT OF TREATMENT IN HEPATITIS B PATIENTS?}

The gold standard endpoints would be improved survival and reduced risk of complications, like cirrhosis, liver failure and HCC. However, these complications often require a longterm study that spans over more than a decade, so are difficult to be proved. Licensing of antiviral medications only require 1 year clinical study and surrogate markers are often used. ${ }^{8}$

\section{HBeAg Positive CHB}

For patients with HBeAg positive CHB, HBeAg seroconversion is considered as an endpoint. $\mathrm{HBeAg}$ seroconversion refers to disappearing of HBeAg, occurrence of anti-HBe, HBV DNA titer dropping below 4 log IU/ml and normalization of transaminases. HBeAg seroconversion is chosen as an endpoint for HBeAg positive $\mathrm{CHB}$ as it signifies resolution of active inflammation and associated with histological improvement and has been shown to lead to better long-term outcome.

\section{HBeAg Negative CHB}

For patients with $\mathrm{HBeAg}$ negative $\mathrm{CHB}$, treatment endpoint is sustained suppression of HBV DNA and HBsAg seroconversion. Unfortunately, HBsAg seroconversion rarely occurs and sustained suppression of HBV DNA usually required long-term treatment. In addition, relapse of HBeAg negative CHB is common when antiviral agents are stopped.

\section{Cirrhosis or HCC Patients}

Continued suppression of HBV DNA titer is important and rebound of HBV DNA titer after cessation of antivirals is almost universal and, hence, patients with cirrhosis or HCC should continue taking antivirals indefinitely.

\section{WHAT TREATMENT IS AVAILABLE FOR CHRONIC HEPATITIS B?}

To date, three injectables (interferons) and five oral antivirals are approved by the FDA, USA, for treatment of CHB.
The first approved treatment for CHB was standard interferon with standard dosage being $5 \mathrm{MU}$ thrice daily. Pegylated interferon, a long-acting interferon, has become available since 2002 and has replaced standard interferon as pegylated interferon is more potent and only required once weekly injection. Randomized controlled trials have showed about 20 to $30 \%$ of patients with HBeAg positive CHB achieved study endpoint, i. e. HBeAg seroconversion; and about 20 to $30 \%$ of patients achieved long-term suppression of HBV DNA in HBeAg negative CHB. There were significant adverse effects associated with interferon or pegylated interferon, such as fever, flu-like symptoms, body ache, hairloss, cytopenia, insomnia, thyroid dysfunction, etc. Besides, it is a costly treatment compared with oral antivirals.

The five antivirals are classified into two families: One family includes lamivudine, telbivudine and entecavir; the other family consists of adefovir and tenofovir. Antivirals are cheaper and have much less adverse effects as compared with interferons.

One year usage of antivirals lead to 15 to $20 \% \mathrm{HBeAg}$ seroconversion in HBeAg positive $\mathrm{CHB}$, but prolonged usage has a diminishing return on increasing rate of $\mathrm{HBeAg}$ seroconversion. For patients with $\mathrm{HBeAg}$ negative $\mathrm{CHB}$, antivirals could drop their HBV DNA to undetectable in most patients with normalization of liver enzymes. Unfortunately, relapse rate is very high when antivirals are stopped. In addition, some patients developed severe flares (called withdrawal flares) when antivirals are stopped. ${ }^{9}$ Hence, many patients continue to take antivirals for many years.

The main drawback is the development of drug-resistant HBV on prolonged usage. Five-year resistance for lamivudine and adefovir are about 70 and $29 \%$, respectively. Two-year resistance for telbivudine is about $20 \%$. Five-year resistance for entecavir is $<2 \%$, whereas 4 -year resistance for tenofovir is zero. ${ }^{10}$ Besides, entecavir and tenofovir are the two most potent antivirals, dropping HBV DNA by about $6 \log$ by 1 year and, hence, are the preferred antivirals for patients with CHB.

\section{WHICH IS THE PREFERRED TREATMENT FOR PATIENTS WITH CHRONIC HEPATITIS B?}

There is no consensus on the best treatment. Many factors may favor the use of interferons vs oral antivirals. ${ }^{11}$

\section{Factors Favoring the use of Pegylated Interferon}

For young patients in the child bearing age, some experts caution about the use of oral antivirals as long-term usage may be indicated which may affect their pregnancy. HBeAg 
positive CHB patients with high transaminases like $>5$ times upper limit of normal, and those with relatively low HBV DNA titer $(<200,000 \mathrm{IU} / \mathrm{ml})$ have a high chance of HBeAg seroconversion when treated with interferons and, hence interferons should be the option of choice. ${ }^{12,13}$

\section{Factors Favoring the use of Oral Antivirals}

HBeAg positive CHB patients with $<2$ times upper limit of normal liver enzymes hardly develop HBeAg seroconversion and should not be treated with interferons. Patients with decompensated liver diseases may worsen during interferons and should be treated with oral antivirals. Patients with uncontrolled thyroid disease, psychiatric illness and autoimmune diseases may deteriorate during interferon treatment and oral antivirals should be used instead.

\section{Choice of Oral Antivirals}

Suboptimal suppression of HBV DNA viral load may encourage development of viral resistance and, hence, the more potent oral antivirals, like tenofovir or entecavir, should be used as first-line treatment. However, their costs are 2 to 3 times higher than that of lamivudine and adefovir and may be prohibitive for many patients. One hepatologists group recommended a roadmap concept whereby a less potent (and also cheaper) antiviral can be used as first-line treatment: Be continued if HBV DNA PCR becomes undetectable by real-time PCR, and to switch to a more potent one if HBV DNA is still detectable. ${ }^{14}$

\section{Combination Therapy}

Several studies have evaluated combining pegylated interferon with lamivudine or adefovir but the results were no better as pegylated interferon alone. One study has compared lamivudine $v$ s lamivudine plus adefovir in treating CHB patients and it showed a lower risk of viral resistance with no increased in treatment response. With more potent antivirals like entecavir or tenofovir which has little chance of viral resistance, combining lamivudine with adefovir, which is less potent does not seem appealing at all. ${ }^{15}$

Currently, combination therapy is not considered as a standard treatment in patients with CHB.

\section{No Consensus on the Best Treatment}

For majority of patients with CHB, either interferons or oral antivirals can be used and clinicians are encouraged to discuss the pros and cons of each treatment with their patients.

Adefovir is associated with renal impairment in about $5 \%$ of patients, and some data are suggesting even tenofovir may be associated with mild renal impairment. It is advisable to monitor patients' renal function regularly to detect any renal abnormality.

\section{WHAT ARE THE OTHER TREATMENT/ INTERVENTIONS NEEDED FOR CHB PATIENTS?}

Clinicians taking care of hepatitis B carriers are encouraged to give nondrug treatment as below:

1. Educate patients on natural history, transmission and potential complications of hepatitis B infection. ${ }^{16,17}$

2. Screen and vaccinate all first-degree relatives, spouse and children.

3. Educate patients on lifestyle risk factors for HCC, namely obesity, excessive alcohol consumption, cigarette smoking.

4. Educate the importance of regular surveillance for complications of hepatitis B, i.e. 6-month follow-up with AFP, liver panel, full blood count testing and ultrasound scanning. ${ }^{18}$

5. Vaccinate them against viral hepatitis A. ${ }^{19}$

\section{CONCLUSION}

CHB is an important medical problem for many Asians, including Bangladeshi. CHB patients should follow with their primary care doctors with regular surveillance of complications. Patients with HCC, cirrhosis or elevated transaminases should be referred to a hepatologist for further management. Currently, eight medications are approved for CHB and hepatologists should weigh the pros and cons of each medication to decide the best treatment on a particular patient.

\section{REFERENCES}

1. Mahtab MA, Rahman S, Karim MF, Khan M, Foster G, Solaiman S, et al. Epidemiology of hepatitis B virus in Bangladeshi general population. Hepatobiliary Pancreat Dis Int Dec 2008;7(6):595-600.

2. Wai CT, Lok AS. Treatment of hepatitis B. J Gastroenterol 2002;37(10):771-78.

3. Lok AS, McMahon BJ. Chronic hepatitis B: Update 2009. Hepatology Sep 2009;50(3):661-62.

4. Kawamoto M, Mizuguchi T, Katsuramaki T, Nagayama M, Oshima H, Kawasaki H, et al. Assessment of liver fibrosis by a noninvasive method of transient elastography and biochemical markers. World J Gastroenterol 21 Jul 2006;12(27):4325-30.

5. Liaw YF, Sung JJ, Chow WC, Farrell G, Lee CZ, Yuen H, et al. Cirrhosis Asian lamivudine multicentre study group. Lamivudine for patients with chronic hepatitis B and advanced liver disease. N Engl J Med 7 Oct 2004;351(15):1521-31.

6. Chan AC, Chok KS, Yuen WK, Chan SC, Poon RT, Lo CM, et al. Impact of antiviral therapy on the survival of patients after major hepatectomy for hepatitis B virus-related hepatocellular carcinoma. Arch Surg June 2011;146(6):675-81. 
7. Chen CJ, Yang HI, Iloeje UH. Reveal-HBV study group. Hepatitis B virus DNA levels and outcomes in chronic hepatitis B. Hepatology May 2009;49(5S):S72-84.

8. Feld JJ, Wong DK, Heathcote EJ. Endpoints of therapy in chronic hepatitis B. Hepatology May 2009;49(5S):S96-S102.

9. Lim SG, Wai CT, Rajnakova A, Kajiji T, Guan R. Fatal hepatitis $\mathrm{B}$ reactivation following discontinuation of nucleoside analogues for chronic hepatitis B. Gut Oct 2002;51(4):597-99.

10. Lok AS, Zoulim F, Locarnini S, Bartholomeusz A, Ghany MG, Pawlotsky JM, et al. Hepatitis B virus drug resistance working group. Antiviral drug-resistant HBV: Standardization of nomenclature and assays and recommendations for management. Hepatology July 2007;46(1):254-65.

11. Sonneveld MJ, Janssen HL. Chronic hepatitis B: Peginterferon or nucleos(t)ide analogues? Liver Int Jan 2011;31(S1):78-84.

12. Hui AY, Chan HL, Cheung AY, Cooksley G, Sung JJ. Systematic review: Treatment of chronic hepatitis B virus infection by pegylated interferon. Aliment Pharmacol Ther 15 Sep 2005;22(6):519-28.

13. Wai CT, Chu CJ, Hussain M, Lok AS. HBV genotype B is associated with better response to interferon therapy in HBeAg $(+)$ chronic hepatitis than genotype C. Hepatology Dec 2002;36(6):1425-30.
14. Woo G, Tomlinson G, Nishikawa Y, Kowgier M, Sherman M, Wong DK, et al. Tenofovir and entecavir are the most effective antiviral agents for chronic hepatitis B: A systematic review and Bayesian meta-analyses. Gastroenterology Oct 2010;139(4):1218-29.

15. Chan HL, Leung NW, Hui AY, Wong VW, Liew CT, Chim AM, et al. A randomized, controlled trial of combination therapy for chronic hepatitis B: Comparing pegylated interferonalpha $2 \mathrm{~b}$ and lamivudine with lamivudine alone. Ann Intern Med 15 Feb 2005;142(4):240-50.

16. Lu W, Mak B, Lim SG, Aung MO, Wong ML, Wai CT. Public misperceptions about transmission of hepatitis B virus in Singapore. Ann Acad Med Singapore Oct 2007;36(10):797-800.

17. Wai CT, Mak B, Chua W, Tan MH, Ng S, Cheok A, et al. Misperceptions among patients with chronic hepatitis B in Singapore. World J Gastroenterol 28 Aug 2005;11(32): 5002-05.

18. Wai CT, Wong ML, Ng S, Cheok A, Tan MH, Chua W, et al. Utility of the health belief model in predicting compliance of screening in patients with chronic hepatitis B. Aliment Pharmacol Ther 15 May 2005;21(10):1255-62.

19. Wai CT, Mak B, Aung MO, Lim SG. Age in guiding strategy in hepatitis A vaccination. Am J Med Aug 2007;120(8):e17-18. 